book, it succeeds in debunking many common critiques of CA, highlighting what comparative CA has accomplished so far, and delineating the promise and the challenges of a very exciting body of research. CACP provides a great introduction to CA for the linguistic anthropologist who may be put off by more rigid CA books. Without doubt, Sidnell's edited volume marks a before and after in the cross-linguistic study of social interaction.

Department of Anthropology

Hunter College, City University of New York

704 Hunter North Building

695 Park Avenue

New York, NY 10065

iclement@hunter.cuny.edu

Bilingual Education in the 21st Century: A Global Perspective. Ofelia García. Malden, MA: Wiley-Blackwell, 2009. pp. xiv +481 .

\author{
ANDREW BABSON \\ University of Michigan
}

Ofelia García, with multiple coauthors, has constructed a useful guide to connections between bilingual education theory, policy and practice, destined for a broad audience. Few recent books have attempted such a broad synthesis; synthesis and connection are, in fact, important motifs of the work itself. That said, the book invites the reader to consider both the pros and cons of being true to synthetic tropes in a reference book for the transdisciplinary field of multilingual education. The book's activist leanings should be welcomed as well as questioned; its attempts to reach a broad audience (policy scholars, linguists, education professionals) succeed in part but also tend toward teleological confusion; and its theoretical framework is a useful tool for seeing how policy and practice are connected, but it is uneven in both its development and application. Overall, the book succeeds as a ready reference on a wide range of bilingual education concepts and national multilingual education policies, yet somewhat less so as a guide to their theoretical bases or practical implementation.

The book is organized into five parts: I, "Bilingual Education for All" (17 pp.), II, "Bilingualism and Education" (88 pp.), III, "Bilingual Education Policy" (178 pp., with Hugo Baetens Beardsmore et al.), IV, “Bilingual Education Practices" (89 pp., with Beardsmore), and V, "Bilingual Education for the $21^{\text {st }}$ Century" (9 pp.). Arguably the most useful part of the book is part III, wherein García, Beardsmore et al. provide snapshots of numerous policy scenarios to varying degrees of detail. Very few books have marshaled together such a wide-ranging comparative picture, which alone would justify the book as a go-to reference. Moreover, these policy snapshots are usefully categorized based on García's theoretical framework, and then described in terms of actual language in education practice in part IV.

García begins the book by providing a certain definition of language and its use, followed by theoretical foundations for this definition; next she shows how this definition has or has not been construed in public policy in a number of global settings; and then, she provides examples of how these construals have been applied in actual educational settings, as a guide to bilingual education pedagogies. García focuses first on what she calls a "monoglossic" definition of languages and their use, contrasting it with a "heteroglossic" definition, and then spends the remainder of the book illustrating how these terms can be applied to describing language use as well as educational policy and practice. The former term stresses the distinctiveness of linguistic codes, and the pragmatic compartmentalization that school curricula may promote; the latter focuses on the fluidity of linguistic distinctions, their political constitution, and the diverse and adaptive uses of language. García argues for privileging a heteroglossic approach as not simply the prerogative of multilingual (and more often than not politically marginalized) learners; rather, multilingualism, as a norm for most of the world's population, should be the norm, period, in all educational settings (p. 5).

If her goal is to show how theory is dynamically linked to policy and practice, she has succeeded in a way that few other reference books on bilingual education have-an important contribution in its own right. But a more robust theorization of the ideological constitution of languages (cf. her section on language ideology, p. 84) might have better served this effort. She appears to interpret language ideology as a set of ideas or attitudes about language without 
making the more productive insight that language ideologies have a social ontological function: they work to define what languages are, and how languages and their uses might establish social distinctions. Pushing this usage of language ideology further, I propose, would provide a firmer foundation for defending bilingual education activism, and show how ideologies are partially and contestably threaded through the connections among language in education theories, policies and practices.

The tangle of terminological confusion around defining "monoglossic" and "heteroglossic" language in education policies illustrates a further opportunity for this insight. One of García's central theoretical arguments is that linguistic codes are not neatly separable, either ontologically or pragmatically. Following this logic, subtractive or additive approaches-whereby a familiar first or "home" language for learners and teachers is either replaced or supplemented, respectively, by a more politically powerful language of wider communication-would be deemed "monoglossic." By contrast, heteroglossic approaches, according to García, reflect the variable "realities" of language practice in multilingual environments more faithfully, while also protecting learners' linguistic rights to deploy a wider range of linguistic code choices across educational settings. Yet García gets tangled in these complex dynamics within the book itself (cf. p. 281, p. 318). The prime example is the use of "bilingual" in the book's title: could there be a more "monoglossic" term for multilingualism? The European Union policy term of "plurilingualism" introduced on pages 54-55 perhaps most faithfully embodies a heteroglossic approach; García's abandonment of this term on page 55 is not convincing.

Another example of the potential usefulness of more attention to language ideology would be far more consideration to the gap between various scholarly and grass-roots visions of linguistic rights. García effectively summarizes the convincing research advocating multilingual education as a political economic or semiotic/cognitive developmental benefit. But in language (use) ecologies where the languages of power such as English are little used or inaccessible, parents' primary demand of educational institutions is to redress this disempowerment. In South Africa, where decentralization of policy decision-making embodies a concern for local agency and social justice, recent data suggest that parental demands for English education would not neatly square with García's model (Emerging Voices: A Report on Rural Communities, Nelson Mandela Foundation, HSRC Press, 2005; Babson, unpublished report, International Literacy Institute, 2007). One must be open-minded about the prospects of a dynamic multilingualist approach in rural South Africa, for example, where generally the quite clear learning benefits of additive multilingualism are still not well communicated to students, parents or education professionals - or worse, smack of Bantu Education redux. The above gap between academic activist and grass-roots educational visions seems connected to the lack of head-on recognition in the book of the wide variety of policy implementation variables and timescales.

One might also be confused by the theoretical and mereological conflict between García's political commitment to heteroglossia (for which she chooses the polyradical banyan tree as an icon) and the book's efforts to be "global" by providing numerous short sketches of "bilingual education policy and practice in X." Can García solidly claim that this is some kind of higherorder indexical statement of commitment to a "global" perspective? García misses a good opportunity to challenge the nation state as a unit of analysis, a longstanding motif in critical studies that has been recently taken up again in comparative international education ("Negotiating Policy in an Age of Globalization: Exploring Educational 'Policyscapes' in Denmark, Nepal, and China," Stephen Carney, Comparative Education Review 53(1), 2009:63-88). García appears especially keen to avoid an OECD-centric treatment of bilingual education, but her approach could easily be taken as a recapitulation rather than rejection of the Western hegemonic taxonomical "view from nowhere."

Indeed, the claim of offering a "global perspective" is limited in this way; but it is also limited by assuming that the " $21^{\text {st }}$ century world" is "interdependent" and "technologically enriched." Ferguson (Global Shadows, Duke University Press, 2006) has usefully argued that what appear to be global connections actually "hop" rather than "flow" between social spaces and serve as nodes of power. Who can argue that for those involved in these nodes and the networks that connect them, the world is certainly "interdependent" and "technologically enriched"? García's book could attend more to the marginalized social spaces across the globe-rural, urban or somewhere in between - that are neither (cf. "The Use of 'Indigenous' and Urban Vernaculars in Zimbabwe," Sinfree Makoni, Janina Brutt-Griffler and Pedzisai Mashiri, Language in Society 36(1), 2007:25-49).

Finally, returning to the issue of teleology and audience, one may wonder if the book attempts too much for too many. For example, much of the policy discussions by Beardsmore 
et al. in part III only draw minimally on the theoretical frameworks presented by García in parts I and II. The authors appear to use the theoretical frameworks to place programs around the world in specific silos; a useful but limited exercise. An approach highlighting four or five detailed localized case studies and using them to draw in the other examples may more usefully explore the realities of language in education practices. García's foundational discussions in parts I and II could be fruitfully complemented by relevant studies in linguistic anthropology or related fields. Finally, though perhaps not of prime interest to linguistic anthropologists, the critically important topic of assessment in multilingual education receives very short shrift.

In sum, despite the above critiques of García's rhetorical strategies and her formulation and application of theoretical frameworks, her book succeeds as a valuable attempt to show how theories, policies and practices are interconnected. Aside from the conceptual issues highlighted above, the detailed discussions of multilingual education policy alone make the book worth buying for scholars of language in education issues.

School of Education

University of Michigan

610 E. University Avenue

Ann Arbor, MI 48104

ababson@umich.edu

Lessons from a Quechua strongwoman: Ideophony, Dialogue and Perspective. Janis $B$. Nuckolls. Tucson: University of Arizona Press, 2010. xvii +229pp.

\section{SIMEON FLOYD}

Max Planck Institute for Psycholinguistics, Nijmegen

With her newest book, Janis Nuckolls revisits her earlier work covering a range of fascinating linguistic anthropological aspects of the oral discourse of speakers of the Pastaza variety of Ecuadorian Quechua, including ideophony, evidentiality and performative aspects of language, and expands and connects these topics in new ways. Her goal in this work is to link language use to themes of humanity in the ecological world of the Amazon rainforest, contributing to the literature on "perspectivism" by highlighting "meaningful, communicative interactions between humans and non-humans" (p. 1). Nuckolls uses the narratives of her primary research consultant Luisa Cadena as a lens for viewing broader cultural issues, an ethnographic strategy that has been used by a number of anthropologists working in lowland Ecuador and other areas of Amazonia (e.g. The Life and Times of Grandfather Alonso: Culture and History in the Upper Amazon, Blanca Muratorio, Rutgers University Press, 1995). Through Luisa, Nuckolls introduces us to the Pastaza Quechua social category of the sindzhi warmi (strong woman), a term applied to women known for their self-determination and resilience. Analyzing a series of narratives of Luisa's life experiences and her reflections on nature and morality, Nuckolls orients her discussion around the three themes mentioned in the book's title: ideophony, dialogue and perspective. While each of these topics yields new insights for the study of language and culture, I found some parts of the argument to cohere more than others. I will treat each of these three topics in turn.

With the first topic, ideophony, Nuckolls is clearly in her element, building on her substantial previous work on the subject, including her groundbreaking book Sounds like Life: Symbolic Grammar, Performance, and Cognition in Pastaza Quechua (Oxford University Press, 1996), which is still the most extensive linguistic anthropological treatment of ideophony to date. I first read this book while staying in a Pastaza Quechua-speaking community, and I remember trying out the vividly-described ideophones in my own speech to wonderful effect; the sensorial and emotive immediacy of the ideophones resulted in amazement, amusement and engagement on the part of my interlocutors, demostrating the insights of Nuckolls' analysis. Now she uses ideophony as a way to explore relationships between humans and other beings, showing how the linguistics of ideophones (grammatical animacy hierarchies, verb aspect, prosody, etc.) provide important resources that Quechua-speakers use in order to align with their environment. She also points out how ideophones are de-valued in institutional and political discourse, and as such might be considered endangered both in cultural and linguistic terms. The 